\title{
Effect of Aerobic Training on Percentage of Body Fat, Total Cholesterol and HDL-C among Obese Children
}

\author{
Dr. Harbans Lal Godara, Chitra Bishnoi \\ TGT P\&HE Kendriya Vidyalaya Sangthan, Kendriya Vidyalaya STPS Suratgarh Rajasthan, India 335805 \\ Research Scholar, University of Rajasthan, Jaipur Rajasthan India 302004
}

\begin{abstract}
The aim of the present research was to determine the effect of aerobic training on Percentage of Body Fat, total Cholesterol (TC) and High Density Lipoprotein Cholesterol (HDL-C) among obese Children. For this purpose, 20 obese Children (age17-25) were selected. The subjects received endurance training only one session in the morning between 6-7 am for three alternate days a week for six weeks. To analyse the collected data,'t'-ratio was used at 0.05 level of confidence. The results showed that there were significant changes in Percentage of Body Fat, TC and HDL-C. It was concluded that the aerobic training is widely believed to induce changes in the lipid profiles and Percentage of Body Fat of Children.
\end{abstract}

Key words: Body Fat, Strength, Lipid Profile, Lean Body Mass (Lbm), Total Cholesterol.

\section{Introduction}

Modern handball requires for player a good physical endurance, parallel it is very important to develop speed and explosive power and force endurance. Handball is also a social game, where next to the good coordination and cleverness comes up to the important place team players good rapprochement and cooperation (Järvekülg, 2002).

Handball is very popular game worldwide and there is a need of high level of physical and physiological fitness to participate at the elite level. Training can improve the performance of the players to achieve the best possible performance. The training has to be formulated according to the principles of periodization. The training induced changes observed in various anthropometric and biochemical variables can be attributed to appropriate load dynamics. Physique and body composition have an important role for playing Handball. The elite Handball players need to maintain an optimum level of haemoglobin to optimise performance. Heart rate response during exercise and recovery can be very useful parameters in monitoring training. Handball involves repeated jumping, blocking, shouting, power throwing, and sifting which require a high level of strength and power. Moreover, the serum level of urea and uric acid may be used as indicates of over training. In addition, regular monitoring of lipid profile of Handball players can provide valuable information about their health, metabolic and cardiovascular status.

This study was focused on the Handball players as the game is popular and played throughout the world. Studies observing the effect of training on anthropometric and biochemical variables of professional Handball players are lacking in India. In view of the above, a study was undertaken to investigate the effect training on anthropometric and biochemical variables of university Handball players.

\section{Subjects and Training}

\section{Material And Methods}

A total of 10 male University of Rajasthan, Jaipur Handball regularly playing competitive Handball (playing for last 4-7 years) volunteered for this study.

Plyometric training should progress gradually from lower intensity to higher intensity drills, especially for individuals who lack a significant strength training background.

Table 1. Intensity of various plyometric exercises.

\begin{tabular}{|l|l|}
\hline Exercise Type & Intensity \\
\hline Depth jumps 32- 48in $(80-120 \mathrm{~cm})$ & High \\
\hline Bounding Exercises & Sub maximum \\
\hline Depth jumps 8- 20in $(20-50 \mathrm{~cm})$ & Moderate \\
\hline Low impact jumps/throws & Low \\
\hline
\end{tabular}

Depth jumps have a very powerful training effect so the volume of work should be low, no more than 4 sets of 10 repetitions, 2-3 times per week for advanced athletes and 3 sets of 5-8 repetitions, 1-2 times per week for lower classes of athletes (Baggett, 1995). A two- or three-day rest (48 hour minimum) between sessions will allow full recovery of the musculoskeletal system and further enhance adaptation. The number of repetitions 
and sets vary depending upon the intensity of the drill. As a rule, a low intensity exercise requires more repetitions. An exercise with a higher degree of difficulty requires fewer repetitions (Brittenham, 1995).

\section{The sample of subjects}

The plyometric training program was applied during 16 week period where was attended ten University of Rajasthan, Jaipur university handball players. Their mean $( \pm \mathrm{SD} 1)$ age, height and mass were 15.5 \pm 2.03 years, $173.9 \pm 9.7 \mathrm{~cm}$ and $65.3 \pm 10.34 \mathrm{~kg}$, respectively (the players characteristics are given in Table 2). They all had four practical trainings and two gym workout trainings sessions a week, and the sessions lasted 60 to 90 minutes. The training sessions were followed 3 days/week, according to the requirement of the game and competitive demand after warming-up, the resting period between exercises series was one minute.

Table 2. Descriptive data of the player's characteristics

\begin{tabular}{|c|c|c|}
\hline Age (y) & Height $(\mathbf{c m})$ & Weight $(\mathbf{k g})$ \\
\hline $17.0 \pm 1.25$ & $182.0 \pm 6.32$ & $73.7 \pm 4.71$ \\
\hline
\end{tabular}

The training schedule, type of training, volume and intensity is shown in Table 1 . The training programme, tests and measurements were conducted according to the standard procedures, having established reliability and validity, adopted by various researchers. Thus the training programme, tests and measurements used were valid. The selected anthropometric and biochemical variables were measured in the laboratory at the beginning of the training (baseline data, BD) and at the end of training Phase. Each test was scheduled at the same time of day ( \pm 1 hour) in order to minimize the effect of diurnal variation. The subjects were informed about the possible complications of the study and gave their consent.

\section{General training schedule for the University handball players. Procedures}

The players had six trainings per week, and three of them had included plyometric training. Training duration was 90 minutes. Prior to each training session, all subjects participated in a 10 minute warm-up period which included jogging at a self-selected comfortable pace followed by calisthenics. After warming-up session players performed plyometric training and after finishing starts with their usual training. All athletes have got instructions how to make exercises correctly before starting plyometric program.

Table 3. Plyometric training exercises program.

\begin{tabular}{ccc} 
Day & Number & Exercise \\
\hline \multirow{3}{*}{ Monday } & $2 \times 10$ & Squat Jumps \\
& $2 \times 10$ & Lateral Box Push Offs \\
& $2 \times 15$ & Overhead Throws \\
$2 \times 10$ & Split Squat Jumps \\
$2 \times 15$ & Power Drop \\
& $2 \times 10$ & Depth Jumps \\
\hline \multirow{3}{*}{ Wednesday } & $2 \times 10$ & Squat Jumps \\
& $2 \times 10$ & Lateral Hurdle Jumps \\
& $2 \times 15$ & Overhead Throws \\
& $2 \times 10$ & Split Squat Jumps \\
& $2 \times 10$ & Plyometric Push-Ups \\
& $2 \times 10$ & Single Leg Lateral Hops \\
\hline \multirow{2}{*}{ Saturday } & $2 \times 10$ & Squat Jumps \\
& $2 \times 10$ & Lateral Box Push Offs \\
& $2 \times 15$ & Overhead Throws \\
& $2 \times 10$ & Split Squat Jumps \\
& $2 \times 15$ & Power Drop \\
& $2 \times 10$ & Depth Jumps \\
\hline
\end{tabular}

Testing procedures

All players participated in three control testing. First measuring was before plyometric training session in July 2013(Base Line data BD). Second testing was after four weeks plyometric training streak in August 2013(pre training programme data PT) and last control measuring has taken 16 weeks after first testing in 
October 2013(after training programme AT) .

1. Standing long jump.

2. Depth leap long jump.

3. Medicine ball throws up in 10 seconds.

4. Medicine ball overhead throws forward against the wall in 10 seconds.

5. Maximal vertical jumps to the maximal height in 10 seconds.

6. Maximal vertical jump height.

\section{Measurement of Anthropometric Variables}

Body mass was measured with an accurately calibrated electronic scale (Seca Alpha 770, UK) to the nearest $0.1 \mathrm{~kg}$, and the stature with a stadiometer (Seca 220, UK) recorded to the nearest $0.5 \mathrm{~cm}$ (Jonson \& Nelson, 1996). Body density (BD) was estimated from the sum of the skin-folds based on the standard procedure (Durnin \& Womersley, 1974). The skin fold measurement was taken from four different sides of the body (biceps, triceps, sub-scapular and suprailiac) using the skin fold calliper on the right side of the body. The estimated percentage body fat was calculated using standard equation (Siri, 1956). Lean body mass (LBM) was calculated by subtracting fat mass from total body mass (Siri, 1956).

$\mathrm{BD}=1.1620-0.0630 \log$ (biceps + triceps + subscapular + suprailliac $)$

Body fat $(\%)=(495 /$ Body density $)-450$

Fat mass $(\mathrm{kg})=[$ Body mass $(\mathrm{kg}) \times$ Body fat $(\%)] / 100$

$\operatorname{LBM}(\mathrm{kg})=$ Body mass - Fat mass

\section{Measurement of Back and grip Strength}

The back and grip dynamometers (Senoh, Japan) were used to record the strength of the back and grip muscles following a standard method (Jonson \& Nelson, 1996). For measurements of back strength, one hand of the subject gripped over and the other under the bar. The hands were spread to the width of shoulders. The trunk was flexed only slightly forward $\left(10^{\circ}-15^{\circ}\right)$ at the hip joints. The body weight was balanced on the feet, which were placed about $15 \mathrm{~cm}$ apart. The knees were kept straight throughout the lift. The lift was performed steadily upwards, without jerking. The subjects were not allowed to lean backwards on the heels. It was ensured that the back was almost straight at the end of the lift. For measurement of grip strength the dryness of the hand and the instrument were ensured. The tester set the pointer to zero and placed the dynamometer in the subject's hand, with the dial against the palm and the larger (concave) pressing edge in the "heel" of the palm. The afterure and positioning of the subjects tested were according to the standard method (Jonson \& Nelson, 1996). The data was obtained with the elbow at $90^{\circ}$ flexion, shoulder at $0^{\circ}$ flexion and wrist between $0^{\circ}$ and $15^{\circ}$ of ulnar and radial deviation. The subject squeezed sharply and steadily as much as possible, making certain that no part of the arm touched the body. For both back and grip strength test three trials were allowed with an interval of two minutes. The test was repeated in case any other deviation from proper procedure was noted. The highest reading of the three trials was recorded in kilograms.

\section{Measurement of Biochemical Variables}

A $5 \mathrm{ml}$ of venous blood was drawn from an antecubital vein after a $12 \mathrm{hrs}$ fast and $24 \mathrm{hrs}$ after the last bout of exercise for subsequent determination of hemoglobin $(\mathrm{Hb})$, serum urea, serum uric acid, total cholesterol (TC), triglycerol (TG), high density lipoprotein-cholesterol (HDL-C) and low density lipoproteincholesterol (LDL-C). Haemoglobin was measured using Cyanmethaemoglobin method (Mukharjee, 1997). Serum urea (Wybenga et al., 1971) and uric acid (Martinek, 1970) were determined calorimetrically using standard procedure. Serum triglycerol (Schettler \& Nussei, 1975), serum total cholesterol (Wybenga, et al., 1970) and HDL-C (Wybenga, et al., 1970) were determined by enzymatic method. LDL-C was indirectly assessed following standard equation (Friedewald et al., 1972).

\section{Statistical analysis}

All the values of anthropometric and biochemical variables were expressed as mean and standard deviation (SD). One Way Analysis of Variance (ANOVA) followed by multiple comparison tests was performed, to find out the significant difference in selected anthropometric and biochemical variables measured before and after the training. In each case the significant level was chosen at 0.05 levels. Accordingly, a statistical software package (SPSS) was used.

\section{Results}

Effect of training on body fat and LBM of Indian University handball players

A significant $(\mathrm{P}<0.05)$ reduction in percent body fat was noted among the Handball players when 
comparing base line data with that of the pre training period and after training period. However, when comparing body fat of pre training period with that of the pre training period no significant change was noted among the players. Further, no significant difference was observed in body mass and LBM of the Handball players after the training programme (Table 4).

Table 5. Effect of Training on Body Fat and Lean Body Mass of Indian University handball Players.

\begin{tabular}{lccc}
\multicolumn{1}{c}{ Parameters } & BD & PT & AT \\
\hline Body Mass $(\mathrm{kg})$ & $67.2 \pm 4.0$ & $66.9^{\mathrm{NS}} \pm 4.9$ & $66.7^{\mathrm{NS}} \pm 4.9$ \\
Body Fat $(\%)$ & $13.8 \pm 1.6$ & $12.4^{*} \pm 1.5$ & $11.8^{*} \pm 1.2$ \\
LBM $(\mathrm{kg})$ & $57.6 \pm 4.2$ & $58.4^{\mathrm{NS}} \pm 3.6$ & $58.4^{\mathrm{NS}} \pm 4.7^{\mathrm{N}}$
\end{tabular}

Note. Data presented as mean $\pm \mathrm{SD} ; \mathrm{n}=10$; Computed using alpha $=0.05$; * when compared to $\mathrm{BD}, \mathrm{BD}=$ base line data, $\mathrm{PT}=$ pre training, $\mathrm{AP}=$ After Training, $\mathrm{NS}=$ not significant; $\mathrm{LBM}=$ lean body mass Effect of training on biochemical variables of University handball players

A significant reduction $(\mathrm{P}<0.05)$ in haemoglobin level was noted in pre training and after training when compared to base line data of the Handball players. When comparing haemoglobin level of pre training with that of the after training no significant change was noted among the players. On the contrary, significant increase $(\mathrm{P}<0.05)$ in serum urea level was noted in pre training and after training when compared to base line data of the Handball players. Comparing serum urea level of pre training with the after training phase no significant change was noted among the players. Further, a significant increase $(\mathrm{P}<0.05)$ in HDL-C level was noted in pre training and after training when compared to base line data of the Handball players. When comparing HDL-C level of pre training with that of the after phase no significant change was noted among the players. On the other hand, significant reduction $(\mathrm{P}<0.05)$ in triglyceride and LDL-C levels was noted in the after phase when compared to base line data of the Handball players. However, when comparing base line data with pre training no significant change was noted in triglyceride and LDL-C levels. In addition, no significant change was noted in serum uric acid and total cholesterol levels of the players after the training (Table 5).

\begin{tabular}{|l|l|l|l|}
\hline \multicolumn{3}{|c|}{ Table 4. Effect of training on biochemical variables of University handball players. } \\
\hline \multicolumn{1}{|c|}{ Parameters } & \multicolumn{1}{c|}{ BD } & \multicolumn{1}{c|}{ DTP } & \multicolumn{1}{c|}{ ATP } \\
\hline Hb $\left(\mathrm{gm} \mathrm{dl}^{-1}\right)$ & $14.7 \pm 0.5$ & $14.2^{*} \pm 0.5$ & $14.2^{*} \pm 0.3$ \\
\hline Urea $\left(\mathrm{mg} \mathrm{dl}^{-1}\right)$ & $30.8 \pm 1.1$ & $32.8^{*} \pm 2.0$ & $33.6^{*} \pm 2.2$ \\
\hline Uric Acid $\left.\mathrm{mg} \mathrm{dl}^{-1}\right)$ & $3.7 \pm 0.3$ & $3.7^{\mathrm{NS}} \pm 0.4$ & $3.8^{\mathrm{NS}} \pm 0.4$ \\
\hline TC $\left(\mathrm{m} \mathrm{dl}^{-1}\right)$ & $154.4 \pm 4.6$ & $152.9^{\mathrm{NS}} \pm 4.5$ & $152.1^{\mathrm{NS}} \pm 4.8$ \\
\hline TG $\left(\mathrm{mg} \mathrm{dl}^{-1}\right)$ & $98.7 \pm 4.2$ & $97.4^{\mathrm{NS}} \pm 4.2$ & $96.1^{*} \pm 4.7$ \\
\hline HDL-C $\left(\mathrm{mg} \mathrm{dl}^{-1}\right)$ & $39.4 \pm 3.2$ & $41.7^{*} \pm 4.7$ & $42.0^{*} \pm 4.1$ \\
\hline LDL-C $\left(\mathrm{mg} \mathrm{dl}^{-1}\right)$ & $93.2 \pm 4.4$ & $91.4^{\mathrm{NS}} \pm 4.1$ & $90.4^{*} \pm 4.8$ \\
\hline
\end{tabular}

Note. Data presented as mean $\pm \mathrm{SD} ; \mathrm{n}=10$; Computed using alpha $=0.05$; * when compared to $\mathrm{BD}, \mathrm{BD}=$ base line data, $\mathrm{DTP}=$ during training programme, $\mathrm{ATP}=$ after training programme, $\mathrm{NS}=$ not significant; $\mathrm{Hb}=$ haemoglobin, $\mathrm{TC}=$ total cholesterol, $\mathrm{TG}=$ triglyceride, $\mathrm{HDL}-\mathrm{C}=$ high density lipoprotein cholesterol, LDL-C $=$ low density lipoprotein cholesterol.

\section{Discussion}

Elite Handball players, in keeping with many other elite athletes, tend to be lean and muscular (Lidor \& Ziv, 2010; Portal et al., 2010; Sheppard et al., 2009). In the present study, a significant $(\mathrm{P}<0.05)$ reduction in percent body fat was noted among the Handball players when comparing base line data with that of the preparatory and after training programmes. The reduction in body fat might be due to the fact that the sportsmen underwent high intensity and volume of training over a period of time, which resulted in lowering of body fat percentage. The possible reason of reduction of body fat was endurance training which increased greater utilization of fat for energetic (Carbuhn et al., 2010; Malousaris et al., 2008). Therefore, it can be stated that Handball players can lose body fat more during pre trainingand after training programme of training. This might be due to intensive training and competition schedule. Before and after the season, during the interval most players have their fat content increased, presumably owing to reduced aerobic activity along with nutritional and behavioural changes (Carbuhn et al., 2010; González-Ravé et al., 2011). Similar findings were reported by other researchers (Carbuhn et al., 2010; González-Ravé et al., 2011). On the other hand, no significant difference was observed in body mass and LBM of the Handball players after the training programme. This might be due to improper optimization of the training load and/or short duration of the 
training. It has been reported that short duration of training has no significant effect of body mass and LBM (Reilly, 1990). Since Handball players, even at the highest levels, tend to have depots of body fat higher than optimal, it seems rational to advise the Handball players to keep their activity profile relatively high especially during the off-season with the aim to stay fit and to prevent increased body adiposity.

In the present study, a significant reduction $(\mathrm{P}<0.05)$ in hemoglobin level was noted in preparatory and after training programmes when compared to base line data of the Handball players. This might be due to the effect of training. The training load was gradually increased from base line to the pre training therefore, reduction in hemoglobin level was observed in this phase. Further, during the after training programme, training load along with the stress of competition was responsible for the declined in hemoglobin level. It can be suggested that the decline in hemoglobin level might be due to haemolysis (Fujitsuka et al., 2005). In addition, exercise training induced reduction in hemoglobin concentration also might be due to hemodilution which is a common physiological effect of endurance training also exist among the well trained athletes due to increased in plasma volume (Neumayr et al., 2005). Similar observations were reported by many researchers. Studies on professional athletes showed that hemoglobin values were higher at the beginning of the competition season, and then declined in well-trained athletes (Ostojic \& Ahmetovic, 2008; Radjen et al., 2011).

Strength is the central component of a Handball training program (Marques et al., 2008, 2009; Sheppard et al., 2009). As vertical jumping and rapid movements are part of the game, therefore, strength is essential for match play (Kasbalis et al., 2005; Marques et al., 2008; Popadic Gacesa et al., 2009). A significant $(\mathrm{P}<0.05)$ increase in back strength and grip strength of right hand (GSR) were noted among the Handball players when comparing the base line data with that of the preparatory and after training programmes. In addition, significant increase $(\mathrm{P}<0.05)$ in grip strength of left hand $(\mathrm{GSL})$ was noted among the Handball players when comparing the base line data with that of the after training programmes. This might be due to the effect of training. The changes in volume and intensity of training modules have shown significant improvement in anaerobic power and strength of the players. During pre training the volume of training was high, and an increase in strength and power training stimulus might be the reason behind the improvement in strength after training. Similar findings were noted by many researchers (Kasabalis et al., 2005; Häkkinen, 1993; Marques et al., 2008; Newton et al., 2006). It has been seen that the application of the training programs using strength and power exercises would be particularly effective in improving performance (Burnham et al., 2010; Gabbett, 2008).

The serum urea and uric acid level has been considered as an indicator of overtraining and protein catabolism (Kargotich et al., 2007; Urhausen \& Kindermann, 2002). In this study, significant increase $(\mathrm{P}<0.05)$ in serum urea level was noted in preparatory and after training programmes when compared to base line data of the Handball players. The highest level of urea was noted in the after training programme when the training load and stress of competition was highest. The possible reason for the increased urea level might be due to increase in training stimulus and increase breakdown of proteins. It is believed that a pronounced increase in the urea concentration indicates strong influence of a training session, whereas normalization of the urea level in blood is an index of time to perform subsequent strenuous training sessions (Urhausen \& Kindermann, 2002). Similar observations have been reported by many researchers (Kargotich et al., 2007; Neumayr et al., 2005). However, no significant change was noted in serum uric acid levels of the players after the training. This might be due to improper optimization of the training load.

Lipids and lipoprotein profile indicate the cardiovascular and the metabolic status of the athlete (Kelley \& Kelley, 2009; Popichev et al., 1997). In the present study, a significant increase $(\mathrm{P}<0.05)$ in HDL-C level was noted in preparatory and after training programmes when compared to base line data of the Handball players. On the other hand, significant reduction $(\mathrm{P}<0.05)$ in triglyceride and LDL- $\mathrm{C}$ levels were noted in the after training programme when compared to base line data of the Handball players. As the training load and stress of competition increased from pre-training period to pre trainingand after training programme, the level of triglyceride and LDL-C were decreased where as the level of HDL-C increased gradually. These changes might be due to training. The possible reason for the reduction in triglyceride and LDL-C; and elevation in HDL-C was that exercise especially, endurance exercise which increased metabolism and utilization of blood lipids and lipoprotein for energy production (Altena et al., 2006; Kelley \& Kelley, 2009; Popichev et al., 1997). However, no significant change was noted in total cholesterol level of the players after the training programme. This might be due to improper optimization of the training load. Our findings are in conformity with the observations of other researchers in their recent studies. Cross-sectional studies also reported an increase in HDL-C level and decrease in triglyceride level after exercise (Kelley \& Kelley, 2009). A recent study showed significant increase in HDL-C level and decrease in LDL-C level, with no change in triglyceride after 9 weeks of training (Degoutte et al., 2006). Another study reported that 4 weeks of aerobic exercise training significantly decreased the levels of total cholesterol, LDL-C, and increased HDL-C (Altena et al., 2006).

\section{Conclusions}


These changes are due to training as well as due to participating in an increasing number of competitions. A specific Handball training programme with the structure and loads described in this study is effective of improving body composition and strength parameters. The training induced changes in anthropometric variables have indirect effect on biochemical variables such as hemoglobin, serum urea and uric acid, lipids and lipoproteins profiles of the Handball players. Regular monitoring of the biochemical variables of the Handball players is essential to optimize their general health, metabolic and cardiovascular status which has direct relation with their performance. The unique profile should be taken into consideration while administering training to the Handball players. It was recommended that a careful selection of anthropometric and biochemical variable should be made when assessing the abilities of adolescent Handball players.

\section{Acknowledgement}

The author sincerely and wholeheartedly acknowledges the contribution of Indian Handball players, the Handball coaches and the colleagues in the laboratory, without whose help the present study would have been very difficult to carry out.

\section{References}

[1]. Al-Hazzaa HM, Sulaiman MA, Al-Matar AJ, et al. Cardiorespiratory fitness, physical activity patterns and coronary risk factors in preadolescent boys. Int J Sports Med 1994; 15 (5): 267-72.

[2]. ALTENA TS, MICHAELSON JL, BALL SD, GUILFORD BL, THOMAS TR. Lipoprotein subfraction changes after continuous or intermittent exercise training. Medicine Science Sports and Exercise. 2006; 38:367-372. doi: 10.1249/01.mss.0000185088.33669.fd [ Back to text]

[3]. ASTRAND PO, RODHAL K. Textbook of work physiology. New York: McGraw-Hill. 1986. BOMPA TO. Periodization training for sports. Champaign, IL: Human Kinetics. 1999.

[4]. Atomi Y, Kuroda Y, Asami T, et al. HDL2-cholesterol of children (10 to 12 years of age) related to $\dot{\mathrm{VO}}{ }_{2 \max }$, body fat, and sex. In: Rutenfranz J, Mocellin R, Klimt F, editors. Children and exercise XII. Champaign (IL): Human Kinetics, 1986: 167-72.

[5]. BURNHAM TR, RUUD JD, MCGOWAN R. Bench press training program with attached chains for female volleyball and basketball athletes. Perceptual Motor Skills. 2010; 110:61-68. doi:

[6]. CARBUHN AF, FERNANDEZ TE, BRAGG AF, GREEN JS, CROUSE SF. Sport and training influence bone and body composition in women collegiate athletes. The Journal of Strength and Conditioning Research. 2010; 24:1710-1717.

[7]. DEGOUTTE F, JOUANEL P, BEGUE RJ, COLOMBIER M, LAC G, PEQUIGNOT JM. ET AL. Food restriction, performance, biochemical, psychological, and endocrine changes in judo athletes. International Journal Sports of Medicine. 2006; 27:9-18.

[8]. DURNIN JVGA, WOMERSLEY J. Body fat assessed from total body density and its estimation from skin fold thickness: measurements on 481 men and women from 16 to 72 years. British Journal of Nutrition. 1974; 32:77-97.

[9]. FRIEDEWALD WT, LEVY RI, FREDRICKSON DS. Estimation of the concentration of low density lipoprotein cholesterol in plasma without use of the preparative ultracentrifuge. Clinical Chemistry. 1972; 18:499-501.

[10]. FUJITSUKA S, KOIKE Y, ISOZAKI A, NOMURA Y. Effect of 12 weeks of strenuous physical training on hematological changes. Military Medicine. 2005; 170:590-594.

[11]. GABBETT TJ. Do skill-based conditioning games offer a specific training stimulus for junior elite volleyball players? The Journal of Strength and Conditioning Research. 2008; 22:509-517.

[12]. GONZÁLEZ-RAVÉ JM, ARIJA A, CLEMENTE-SUAREZ V. Seasonal changes in jump performance and body composition in women volleyball players. The Journal of Strength and Conditioning Research. 2011; 25:1492-1501.

[13]. HÄKKINEN K. Changes in physical fitness profile in female volleyball players during the competitive season. The Journal of Sports Medicine and Physical Fitness. 1993; 33:223-232.

[14]. Hofman A, Walter HJ. The association between physical fitness and cardiovascular disease risk in children in a five-year follow-up study. Int J Epidemiol 1989; 18 (4): 830-5.

[15]. INBAR O, BAR-OR O, SKINNER J. S. The Wingate anaerobic test. Champaign IL: Human Kinetics. 1996.

[16]. JONSON BL, NELSON JK. Practical measurements for evaluation in physical education. London: Macmillan Publishing Co. 1996

[17]. KARGOTICH S, KEAST D, GOODMAN C, BHAGAT CI, JOSKE DJ, DAWSON B. et al. Monitoring 6 weeks of progressive endurance training with plasma glutamine. International Journal Sports and Medicine. 2007; 28:211-216.

[18]. KASABALIS A, DOUDA H, TOKMAKIDIS SP. Relationship between anaerobic power and jumping of selected male volleyball players of different ages. Perceptual Motor Skills. 2005; 100:607-614.

[19]. KELLEY GA, KELLEY KS. Impact of progressive resistance training on lipids and lipoproteins in adults: a meta-analysis of randomized controlled trials. Pre Med. 2009; 48:9-19.

[20]. KNEFFEL Z. Morphological and functional characteristics of the left ventricle in athletes of various ages, and performing at various levels. Orv Hetil. 2008; 149:1085-1094.

[21]. Kwee A, Wilmore JH. Cardiorespiratory fitness and risk factors for coronary artery disease in 8- to 15-year-old boys. Pediatr Exerc Sci 1990; 2: 372-83.

[22]. LIDOR R, ZIV G. Physical characteristics and physiological attributes of adolescent volleyball players-a review. Pediatrics Exercise Science. 2010; 22:114-134.

[23]. Mácek M, Bell D, Rutenfranz J, et al. A comparison of coronary risk factors in groups of trained and untrained adolescents. Eur J Appl Physiol 1989; 58: 577-82.

[24]. MALOUSARIS GG, BERGELES NK, BARZOUKA KG, BAYIOS IA, NASSIS GP, KOSKOLOU MD. Somatotype, size and body composition of competitive female volleyball players. Journal Science Medicine of Sport. 2008; 11:337-344.

[25]. MARQUES MC, TILLAAR R, VESCOVI JD, GONZÁLEZ-BADILLO JJ. Changes in strength and power performance in elite senior female professional volleyball players during the in-season: a case study. The Journal of Strength and Conditioning Research. 2008; 22:1147-1155

[26]. MARQUES MC, VAN DEN TILLAAR R, GABBETT TJ, REIS VM, GONZÁLEZ-BADILLO JJ. Physical fitness qualities of professional volleyball players: determination of positional differences. The Journal of Strength and Conditioning Research. 2009; 23:1106-1111.

[27]. MARTINEK RG. Review of methods for determining inorganic phosphorus in biological fluids. The American Journal of Medical 
Technology. 1970; 32:237.

[28]. MUKHARJEE KL. Medical laboratory technology. A procedure manual for routine diagnostic tests.

[29]. NEUMAYR G, PFISTER R, HOERTNAGL H, MITTERBAUER G, PROKOP W, JOANNIDIS M. Renal function and plasma volume following ultra marathon cycling. International Journal of Sports Medicine. 2005;

[30]. NEWTON RU, ROGERS RA, VOLEK JS, HAKKINEN K, KRAEMER WJ. Four weeks of optimal load ballistic resistance training at the end of season attenuates declining jump performance of women volleyball players. The Journal of Strength and Conditioning Research. 2006; 20:955-961.

[31]. Nizankowska-Blaz T, Abramowicz T. Effects of intensive physical training on serum lipids and lipoproteins. Acta Paediatr Scand 1983; 72: 357-9.

[32]. OKAZAKI FH, KELLER B, FONTANA FE, GALLAGHER JD. The relative age effect among female Brazilian youth volleyball players. Research Quarterly for Exercise \& Sport. 2011; 82:135-139.

[33]. OSTOJIC SM, AHMETOVIC Z. Weekly training volume and hematological status in female top-level athletes of different sports. Journal Sports Medicine Physical Fitness. 2008; 48:398-403.

[34]. POPADIC GACESA JZ, BARAK OF, GRUJIC NG. Maximal anaerobic power test in athletes of different sport disciplines. The Journal of Strength and Conditioning Research. 2009; 23:751-755.

[35]. POPICHEV MI, TOLKACHEVA NV, KULAKOVA SN, KONOSHENKO SV. Lipid composition of blood plasma and erythrocyte membrane of volleyball players under intensive physical load. Ukr Biokhim Zh. 1997; 69:83-87.

[36]. Smith BW, Metheny WP, Sparrow AW. Serum lipid and lipoprotein profiles of elite age-group runners. In: Weiss MR, Gould D, editors. Sport for children and youths. Champaign (IL): Human Kinetics, 1986: 269-73.

[37]. Suter E, Hawes MR. Relationship of physical activity, body fat, diet, and blood lipid profile in youths 10-15 yr. Med Sci Sports Exerc 1993; 25 (6): 748-54

[38]. Tell GS, Vellar OD. Physical fitness, physical activity, and cardiovascular disease risk factors in adolescents: the Oslo Youth Study. Prev Med 1988; 17: 12-24.

[39]. Thorland WG, Gilliam TB. Comparison of serum lipids between habitually high and low active pre-adolescent males. Med Sci Sports Exerc 1981; 13 (5): 316-21.

[40]. Tolfrey K, Campbell IG, Jones AM. Predictor variables and the lipid-lipoprotein profile in prepubertal girls and boys. Med Sci Sports Exerc 1999; 31 (11): 1550-7.

[41]. Vol I - III. New Delhi: Tata McGraw-Hill Pub Com Ltd. 1997.

[42]. Zonderland ML, Erich WBM, Peltenburg AL, et al. Apo lipoprotein and lipid profile in young female athletes. Int J Sports Med 1984; 5: 78-82. 